\title{
Detection of Fakes: The Merits and Limits of Non-Invasive Materials Analysis
}

\begin{abstract}
This paper addresses the sensitive issue of authenticating unprovenanced manuscripts of high monetary value to certify they are genuine. Over the last decade, the popularity of material studies of manuscripts using non-destructive testing (NDT) has increased enormously. These studies are held in especially high esteem in the case of suspicious writings due to the methodological rigour they are reputed to contribute to debate. We would like to stress that materials analysis alone cannot prove that an object is genuine. Unfortunately, audiences with a humanities background often tend to disregard the technical details and treat any published interpretation of instrumental analysis as an objective finding. Four examples are outlined here to illustrate what questionable contributions the natural sciences can make in describing manuscripts that have actually been forged.
\end{abstract}

Today it is difficult to pinpoint the beginnings of instrumental analysis in the world of archaeology and art, but the growing number of scientific papers appearing by the end of the nineteenth century testifies to the onset of its popularity. It seems that metal studies of prehistoric finds in the 1870 s belong to the earliest documented chemical investigations. In 1888, the first chemical laboratory to assist with conservation was opened in Berlin: the Rathgen Research Laboratory. Scientific studies in archaeology and conservation became established over the next fifty years, mostly concerning Egyptology, as witnessed by numerous editions of the standard textbook Ancient Egyptian Materials and Industries, first published by Alfred Lucas in 1926 (Lucas/Harris 1962). It is not surprising that the natural sciences came to play an important role in examining artefacts of questionable authenticity.

Moreover, studies in art and archaeology involving experiments performed by members of the natural science community are held in high esteem due to the methodological rigour they are reputed to contribute to debate. And yet, as Jeffrey Spier has said in his article 'Blinded with science: the abuse of science in the detection of false antiquities’:

Ә Open Access. (C 2020 Ira Rabin, Oliver Hahn, published by De Gruyter. (cc) BY-NC-ND This work is licensed under the Creative Commons Attribution-NonCommercial-NoDerivatives 4.0 International License.

https://doi.org/10.1515/9783110714333-013 
Many technical and scientific studies, however, are not conclusive, especially in determining authenticity, and often appear to be invoked by archaeologists as a desperate appeal to the unattainable, 'objective' result rather than as a proper study.

(Spier 1990, 623).

Despite this warning and the plea for cautiousness, the popularity of such studies has increased enormously over the last two decades due to the industry-driven development of non-destructive technology (NDT), which does not require any sampling. Further technological developments led to the appearance of NDT methods with extremely small interaction windows (in the $\mu \mathrm{m}$ range). These methods have obvious limitations when they are employed to analyse objects whose composition displays heterogeneity of the same order of magnitude. Scanning mode or a statistically relevant number of points establishing characteristic material properties of the area under study are used to overcome the limitations. Nevertheless, their random application in a single-spot measurement is rather common. Obviously, implementation of such methods requires specific protocols to be used that take heterogeneity and possible degradation pathways into consideration. A materials scientist with experience in archaeometry is certainly familiar with such problems and would be able to avoid the pitfalls of misinterpreting the complex analytic results.

In general, the fulfilment of the following requirements is indispensable for authentication issued by an accredited technical authority: standard references, certified procedures and characteristic samples. It is patently clear that the prerequisites mentioned above can rarely be found when dealing with unique objects belonging to cultural heritage, meaning that no certificate of authenticity can be issued. It does not mean, however, that we know nothing about the production technologies, writing materials or painters' palettes of the past. Equipped with existing databases, experts working in forensics and archaeometry are often capable of identifying a forgery as it is often betrayed by anachronistic details: the use of paints unknown at the time or incompatible with the period, or the use of paper containing whiteners that were either tampered with or developed recently. However, we cannot automatically come to the conclusion that the object under scrutiny is authentic if nothing suspicious is found.

On one hand, the ever-growing number of materials studies is helping researchers to characterise the materials used in cultural heritage. On the other hand, studies of this kind are also helping to produce sophisticated forgeries that cannot be identified easily. It has become fashionable to conduct a non-invasive analysis as part of a technical examination of a suspicious object. In many cases, however, the results of such an investigation have not been particularly helpful. The following four case studies serve to illustrate this point. 


\section{The Gospel of Jesus' Wife}

At the Tenth International Congress of Coptic Studies held in Rome in September 2012, Professor Karen King from Harvard Divinity School presented a new Coptic Gospel fragment to the audience (King 2014, Camplani 2012). The papyrus fragment, which is approximately $4 \times 8 \mathrm{~cm}$ in size (Fig. 1), allegedly belonged to a fourth-century copy of a Coptic translation of the Gospel and contained an indication that Jesus was married. During the four years of scholarly controversy that followed the appearance of the sensational fragment and which was skilfully spurred by the media, it received the name Gospel of Jesus' Wife (or 'GJW' for short). In June 2016, Ariel Sabar's investigation published in The Atlantic magazine proved unequivocally that the fragment was actually a modern forgery (Sabar 2016). What makes the story interesting is the use - or rather, misuse - of the results of materials analysis in the attempt to prove that the manuscript was genuine.

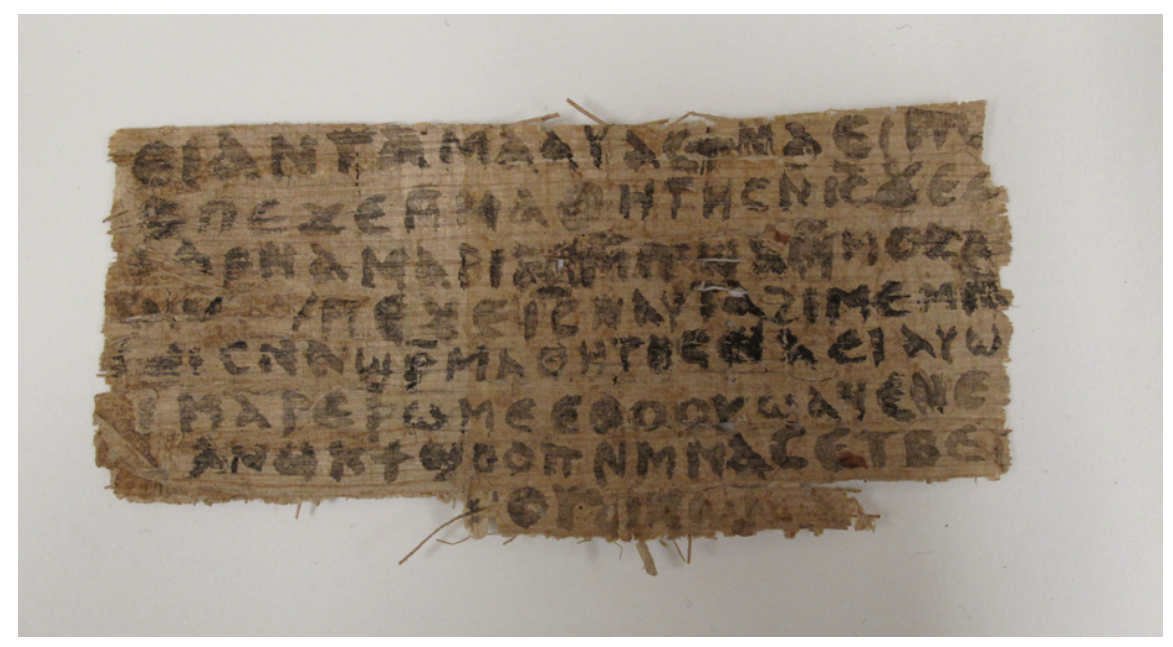

Fig. 1: Gospel of Jesus's Wife (papyrus fragment), Recto; (C Harvard University

Issue 2 of volume 107 of the Harvard Theological Review was dedicated almost entirety to the question of the fragment's authenticity, with four papers reporting the results of the materials analysis conducted on (a) the papyrus writing support using Fourier Transform Infrared Spectroscopy (FTIR) in reflection mode (Azzarelli et al. 2014); (b) black inks with Raman spectroscopy (Yardley/Hagadorn 2014); 
(c) and (d) radiocarbon dating of papyrus (Hodgins 2014; Tuross 2014). In the first two studies, the investigations included the suspicious fragment and control material for comparison. Two radiocarbon dating tests were conducted on the fragment and the control fragment from the Gospel of John. Radiocarbon dating first conducted in the Arizona Accelerator Mass Spectrometry (AMS) Laboratory failed to produce a reasonable date due to contamination, and suggested redating the fragment. The second radiometric measurement conducted at the National Ocean Sciences Accelerator Mass Spectrometry (NOSAMS) Laboratory in Massachusetts dated the material (papyrus) to the eighth century. This result effectively disputed the initial claim that the Gospel of Jesus' Wife originated from an early Christian manuscript. Moreover, it suggested that the fragment from the Gospel of John, which had hitherto served as an impeccable reference, could be a modern forgery. It was in fact confirmed later since it was written in a dialect that no longer existed in the eighth century CE (Askeland 2015).

In comparison, the non-destructive spectroscopy tests, (a) and (b), delivered rather meagre results. The first one found that the main material of which the writing supports were made was papyrus, that it could be old and that it was homogeneous in its chemical composition. This means that all the spectra measured in this study indicated that the material was papyrus, i.e. no contamination could be detected in fourteen random spots $100 \times 100 \mu \mathrm{m}$ in size on the inked and noninked portions of the supports. Ancient papyrus rarely displays homogeneity, however - it usually contains uneven distributions of salts or other mineral deposits that are best assessed by micro-X-ray fluorescence (micro-XRF) in scanning mode rather than by investigating a dozen micro-spots with a technique only capable of detecting the main material.

In the second study, the Raman spectra of the inks used in the 'Gospel of Jesus' Wife' and the Gospel of John were first compared qualitatively to those collected from commercial lamp-black and vine-black pigments. In a second step, the Raman spectra were analysed to obtain a quantitative comparison of the inks from the two papyri in question. The authors concluded that the inks from the two fragments only contained soot (lamp black) as a colouring agent, that they differed from each other and that they were very similar to the dated ancient inks, gently implying that the inks in question could, indeed, be ancient. In other words, this study suggested that Raman spectroscopy could not only be used to differentiate between lamp-black pigments, but for their non-destructive dating as well. This was a sensational result without a doubt. Unfortunately, the proof provided later that both inks were modern forgeries strongly compromised the authors' conclusions (Sabar 2016). More generally, there is no possibility of dating carbon inks using Raman spectroscopy. 
Destructive radiometric dating of the papyrus substrates is the only investigation in this series that contributed fruitfully to the debate. It also shows that it is not that easy to buy an old piece of papyrus of the right age. In this respect, easy accessibility to radiometric dating could be extremely helpful to forgers. Consequently, many scientists are now considering whether to issue a ban on dating unprovenanced material in the hands of antiquity dealers (Huysecom et al. 2017).

\section{The Vinland map}

In contrast to the previous example, Raman spectroscopy played a decisive role in identifying the Vinland map (Fig. 2) as a modern forgery, thus ending a scholarly debate that had lasted over forty years.

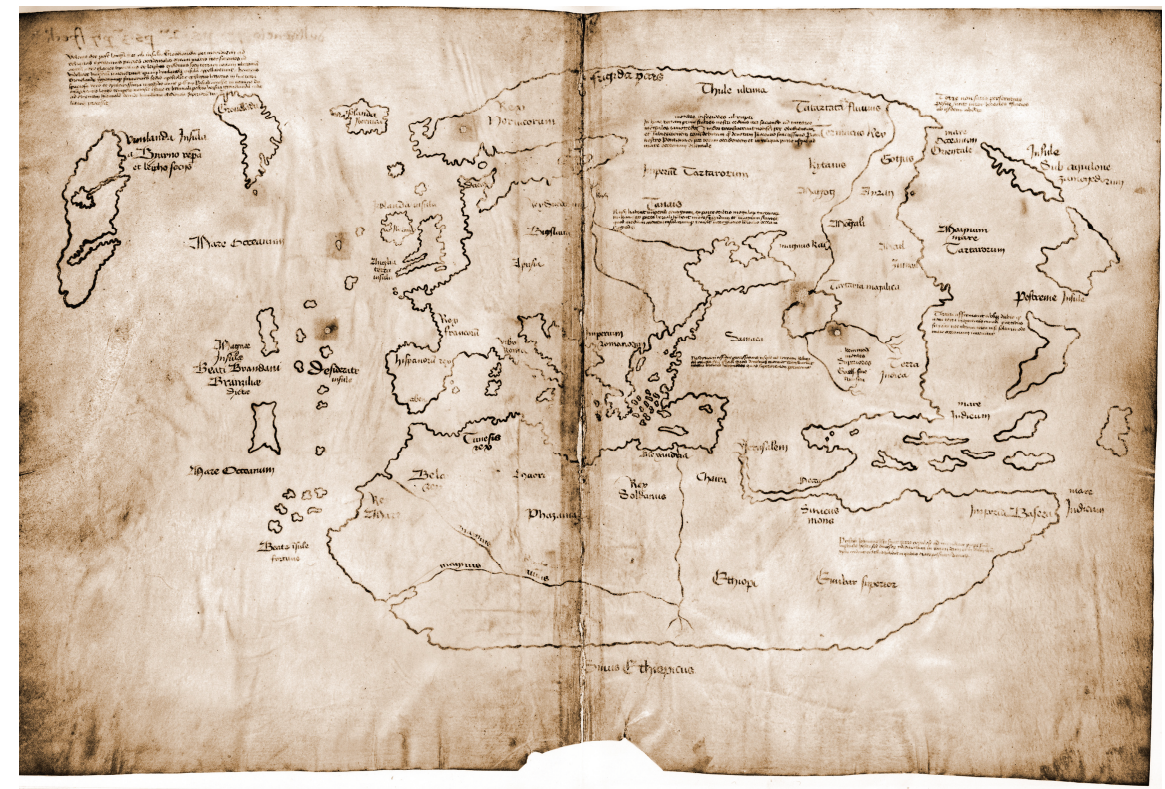

Fig. 2: Vinland Map (Hystoria Tartarorum); @ General Collection, Beinecke Rare Book and Manuscript Library, Yale University.

One day in 1957, a fifteenth-century map came to light that contained an accurate depiction of the coastlines of Greenland and Newfoundland along with a Viking 
voyage made around the year 1000 in order to discover Vinland. If it was authentic, it would have meant that Vikings discovered America around 500 years before Columbus (Charney 2015, 226-230). Using Raman microprobe spectroscopy in 2001, Katherine Brown and Robin Clark from University College London found that the ink on the map contained modern pigment in addition to carbon-based ink (Brown/Clark 2002). In this case, then, a single analysis was able to prove that the manuscript in question was a modern forgery.

\section{Privilegium maius}

In the third case study, a series of non-invasive and micro-invasive analytical tests were conducted on five parchment charters known by the name of Privilegium maius and currently preserved in the Austrian State Archive (AUR 98, AUR 187, AUR 520, AUR 708 and AUR 1845). These were allegedly signed in 1058, 1156, 1228, 1245 and 1283 respectively (see Fig. 3). The charters substantiate the Habsburg claim to the elite circle of the prince-electors of the Holy Roman Empire, but are believed to be a forgery produced in the Habsburg chancellery in 1358-1359 by order of Duke Rudolph IV of Austria. Basing his conclusions on anachronistic details, Wilhelm Wattenbach identified the charters as forgeries from the time of Rudolph IV (Wattenbach 1852).

Scientific investigations conducted recently in the Austrian State Archive in the course of preparing an exhibition on the Privilegium maius included X-ray radiography, infrared reflectography and diagnostic photography (Strolz/Griesser 2018), identification of the animal precursor of the parchment using microscopic analysis and proteomics (Vnouček/Fiddyment 2018), elemental analysis of the writing inks with micro-X-ray fluorescence analysis (micro-XRF, Uhlir 2018) and chemical analysis of the inks and coloured seal threads with ultraviolet-visible fibre-optic reflectance spectrophotometry (Aceto et al. 2018). For a complete evaluation of the chemistry underlying dyeing of the threads, extracted microscopic samples were subjected to testing with conventional and surfaceenhanced Raman spectroscopy (SERS) as well as high-performance liquid chromatography coupled with diode-array detection and mass spectrometry (HPLC-DAD-MS). Unlike the majority of cases that scientists investigate in which one asks whether the object under examination could be a fake, in this one, the study was expected to offer insights about the materials the forgers used. Since the documents were believed to have been produced in one and the same workshop, the investigators were more interested in finding out what materials the forgers employed than in confirming the act of forgery itself. The study has 
shown, however, that all the inks used to produce the documents were different in terms of their relative elemental composition. Furthermore, it was found that the threads were not dyed in the same bath. All in all, one comes to a striking result that the charters were not produced in one stage or even in the same workshop, raising the question how the forgery was conducted.

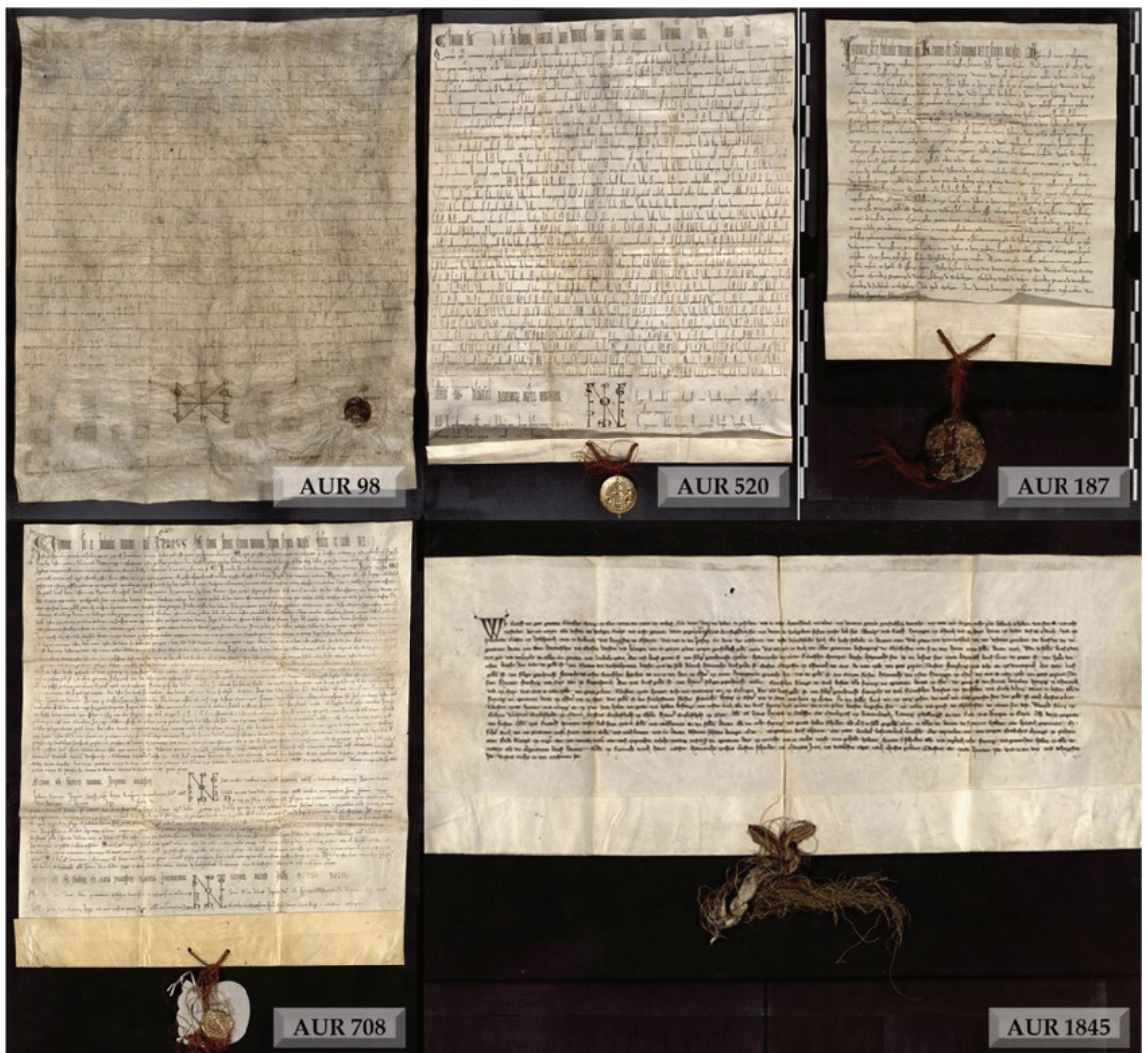

Fig. 3: Five parchment charters constituting the Privilegium maius; (C) Österreichisches Staatsarchiv.

We should not forget, though, that the task was far from easy, especially if we take into account that the documents under study are at least 650 years old. To identify anachronistic details in the production of these documents, one would expect to be able to differentiate between the materials and production technologies used in a period of 300 years during the Middle Ages. To meet such a 
requirement, one would have to study a statistically relevant number of documents from the period in question and establish the degree of variance of the inks and dyes used. We hope that the results presented in this work would serve as a starting point for a larger project dedicated to the study of medieval inks.

\section{Galileo's Sidereus Nuncius}

One other striking case is that of the so-called galley proofs of Galileo's Sidereus Nuncius, a revolutionary work in which the scientist experimentally confirmed the theory that Copernicus had proposed. In addition, the book, which was printed for the first time in Venice in 1610 in some 550 copies, contained copperplate etchings of the moon that depicted its surface based on Galileo's telescopic observations. Unlike other extant copies, the New York one containing watercolours instead of etchings caused a great deal of excitement in scholarly circles. After its discovery in 2007 no suspicions were raised by the experts, who immediately started to study the book and even solicited paper-and-ink analyses from scientists to complement their scholarly research. As is customary in such cases, all the analyses had to be conducted in a non-destructive way despite the known limitations of such an approach. Although the scientists were offered two other uncontested copies, there were no ink samples of the inscription or drawings for comparison. Like the case of the GJW, the mere thought of having discovered Galileo's original drawings seems to have caused the scholars working on this book to miss or ignore a number of idiosyncrasies revealed by the scientific analysis. The more scholars studied the volume, however, the more anomalies were found. One of these - the word periodis printed as pepiodis (Fig. 4) with a ligature pi that did not appear in any other copy - revealed that the 'galley proofs' were modern copies produced with the help of photopolymer plates. Following this discovery in 2012, the original team of researchers undertook another series of tests. The results were published as a sequel to the previous volumes on the alleged galley proofs, which 'describes the chronology and methods by which the discovery of forgery was made - a veritable watershed moment in the continuing struggle between the ever-more refined methods of forgers and new methods used to apprehend them. Ultimately, the work also provides insight into the psychology of specialists who "research themselves" in order to prevent similar errors in the future' (Bredekamp et al. 2014, flyer). 


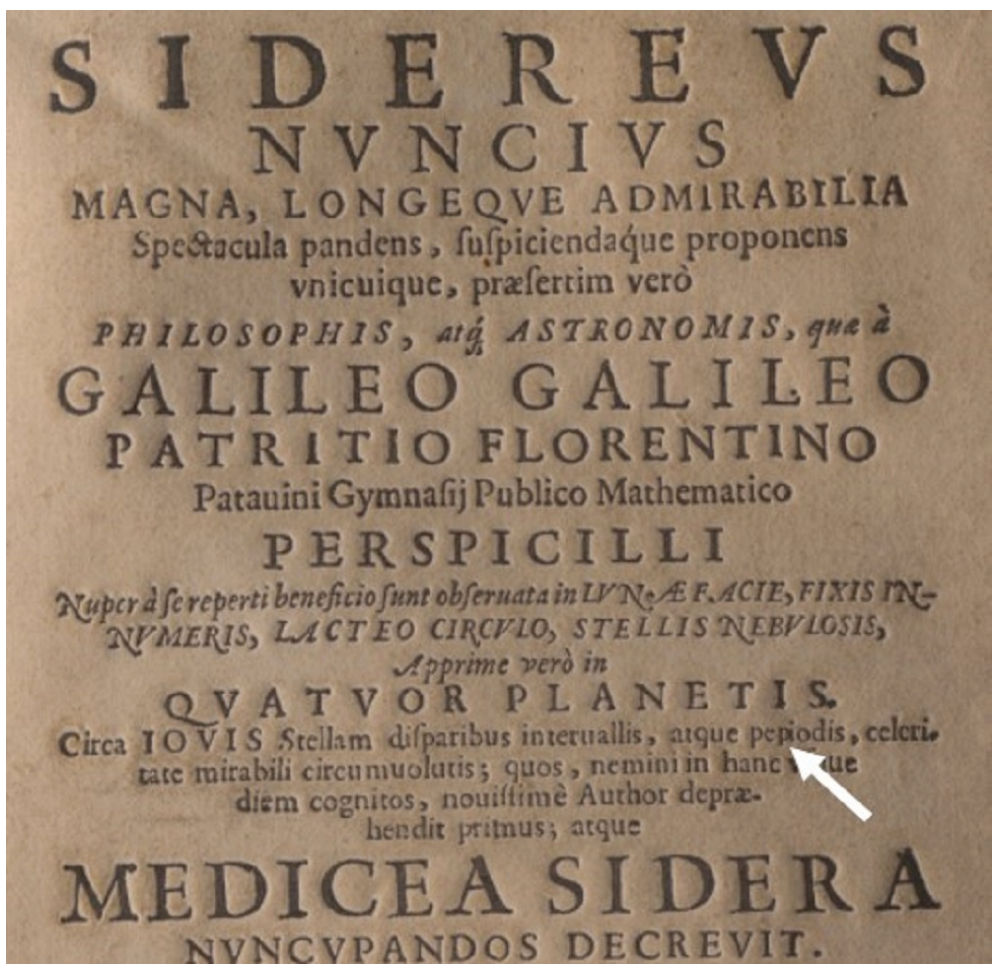

Fig. 4: Close-up showing part of the front page of the 'galley proofs' of Galileo's Sidereus Nuncius; (C) image: Barbara Herrenkind, Berlin. The white arrow indicates the word 'pepiodis'.

\section{Conclusion}

To summarise, then, we would like to return to the sensitive issue of authenticating objects of great cultural and monetary value - certifying that they are genuine. Sometimes it is possible to identify forgeries beyond a shadow of doubt when non-contemporary materials were used to produce it. We would like to stress, however, that materials analysis alone, especially its non-destructive variety, cannot verify the authenticity of an object, i.e. prove that it is genuine. The best that materials analysis can do, after all appropriate tests have been conducted, is to announce that nothing has been found that contradicts the assumption of genuineness. 


\section{References}

Aceto, Maurizio, Elisa Calà, Patrizia Davit, Monica Gulmini, Ambra Idone, Annalisa Salis, and Gianluca Damonte (2018), 'Analytical investigation of the inks and dyes used in the Privilegium maius', in Technologische Studie, 13: 112-133.

Askeland, Christian (2015), 'A Lycopolitan Forgery of John's Gospel', in New Testament Studies, 61: 314-334.

Azzarelli, Joseph M., John B. Goods, and Timothy M. Swager (2014), 'Study of Two Papyrus Fragments with Fourier Transform Infrared Microspectroscopy', in Harvard Theological Review, 107/2: 165.

Bredekamp, Horst, Irene Brückle, and Paul Needham (eds) (2014), A Galileo Forgery. Unmasking the New York Sidereus Nuncius, Berlin: De Gruyter.

Brown, Katherine L. and Robin J. H. Clark (2002), 'Analysis of Pigmentary Materials on the Vinland Map and Tartar Relation by Raman Microprobe Spectroscopy', in Analytical Chemistry 74 (15), 3658-3661.

Camplani, Alberto (2012), 'Jesus' wife: a papyrus adrift', in Manuscript of the Month, 10 <https://www.manuscript-cultures.uni-hamburg.de/mom/2012_10_mom_e.html (last accessed 7/5/2020).

Charney, Noah (2015), The Art of Forgery, London: Phaidon Press.

Hodgins, Gregory (2014), 'Accelerated Mass Spectrometry Radiocarbon Determination of Papyrus Samples', in Harvard Theological Review, 107/2: 166-169.

Huysecom, Eric, Irka Hajdas, Marc-André Renold, Hans-Arno Synal, and Anne Mayor (2017), 'The "enhancement" of cultural heritage by AMS dating: ethical questions and practical proposals', in Radiocarbon, 59: 559-563.

King, Karen L. (2014), 'Jesus said to them, “My wife...”: A New Coptic Papyrus Fragment', in Harvard Theological Review, 107/2: 131-159.

Lucas, Alfred and John H. Harris (1962), Ancient Egyptian Materials and Industries, Mineola, NY: Dover Publications.

Sabar, Ariel (2016), ‘The Unbelievable Tale of Jesus's Wife', in The Atlantic, July/August 2016: 64-78.

Spier, Jeffrey (1990), 'Blinded with science: the abuse of science in the detection of false antiquities', in The Burlington Magazine, 132: 623-631.

Strolz, Monika and Martina Griesser (2018), 'Die Untersuchungen mittels strahlendiagnostischer Verfahren', in Technologische Studien, 13: 54-81.

Tuross, Noreen (2014), 'Accelerated Mass Spectrometry Radiocarbon Determination of Papyrus Samples', in Harvard Theological Review, 107 (2), 170-171.

Uhlir, Katharina (2018), 'Die Tinten: Untersuchungen mittels energiedispersiver Röntgenfluoreszenzanalyse', in Technologische Studien, 13: 94-111.

Vnouček, Jiři and Sarah Fiddyment (2018), 'On the parchment of the Privilegium maius charters', in Technologische Studien, 13: 82-93.

Wattenbach, Wilhelm (1852), Die österreichischen Freiheitsbriefe: Prüfung ihrer Echtheit u. Forschungen über ihre Entstehung, Berlin: Hertz in Komm.

Yardley, James T. and Alexis Hagadorn (2014), 'Characterization of the Chemical Nature of the Black Ink in the Manuscript of The Gospel of Jesus's Wife through Micro-Raman Spectroscopy', in Harvard Theological Review, 107/2: 162-164. 